\title{
Effect of the components of the metabolic syndrome on pulmonary function. The unexpected role of high-density lipoprotein cholesterol
}

\author{
Efecto de los componentes del síndrome metabólico en la función pulmonar. El \\ inesperado papel del colesterol ligado a lipoproteínas de alta densidad
}

\author{
Saúl Huerta-Ramírez ${ }^{*}$, Angélica Paniagua-Pérez², David Castro-Serna1, Andrés Ledesma-Velázquez', \\ Alberto Rubio-Guerra ${ }^{3}$ and Germán Vargas-Ayala ${ }^{1}$ \\ ${ }^{1}$ Internal Medicine Department, SEDESA, Hospital General Ticomán; ${ }^{2}$ Internal Medicine Department, Hospital General de Zona 58, Instituto Mexicano \\ del Seguro Social; ${ }^{3}$ Teaching and Research Head Office, SEDESA, Hospital General Ticomán. Mexico City, México
}

\begin{abstract}
Background: Metabolic syndrome is a condition that predisposes to cardiovascular disease and diabetes mellitus. In addition, it can have effects over neoplastic pathologies, liver and pulmonary function. Our objective is to analyze the effect of the metabolic syndrome and its components on pulmonary function. Method: 110 subjects from Mexico City were evaluated and anthropometric measurements, glucose determination, triglycerides and high-density lipoprotein (HDL) cholesterol were made. They underwent a simple spirometry. Diagnosis of metabolic syndrome was made following the NCEP-ATPIII criteria. Results: Of 110 individuals, 90 (82\%) were women and 20 men (18\%); 71 subjects (65\%) presented metabolic syndrome. Subjects with central obesity had a forced vital capacity (FVC) lower than subjects without central obesity (2.72 vs. 3.11 liters; $p<0.05)$. Those with low HDL had better spirometric results than subjects with normal HDL (FEV1 2.36 vs. 1.85 liters; $p<0.05), F V C$ (2.95 vs. 2.45 liters; $p<0.05$ ) and FEV1/FVC ratio (0.78 vs.74; $p<0.05)$. Hypertensive subjects presented lower volumes in FEV1 $(1.91$ vs. $2.38 ; p<0.05)$ and FVC (2.49 vs. 2.99; $p$ < 0.05). Conclusion: There is no difference between the spirometry volumes of patients with metabolic syndrome versus the metabolically healthy subjects. The only factors associated with a decrease in FEV1 and FVC are central obesity and arterial hypertension. An unexpected finding was the negative correlation between HDL levels and lung function.
\end{abstract}

KEY WORDS: Spirometry. Metabolic syndrome. Lung. HDL cholesterol.

\section{Resumen}

Antecedentes: El síndrome metabólico es un estado que predispone a enfermedad cardiovascular y diabetes mellitus. Además, puede repercutir en la función hepática, en patologías neoplásicas y en la función pulmonar. Nuestro objetivo es analizar el efecto del síndrome metabólico y sus componentes sobre la función pulmonar. Método: Se evaluaron 110 sujetos de la Ciudad de México a quienes se realizaron mediciones antropométricas, determinación de glucosa, triglicéridos y colesterol ligado a lipoproteínas de alta densidad (HDL). Se les practicó una espirometría simple. Se realizó el diagnóstico de síndrome metabólico siguiendo los criterios NCEP-ATPIII. Resultados: De 110 individuos, 90 (82\%) fueron mujeres y 20 hombres (18\%), y 71 (65\%) presentaron síndrome metabólico. Los sujetos con obesidad central tuvieron una capacidad vital forzada (CVF) menor que aquellos sin obesidad central (2.72 vs. 3.11 l; $p<0.05)$. Los que presentaron colesterol HDL bajo tuvieron mejores resultados espirométricos que los sujetos con colesterol HDL normal (volumen espiratorio forzado en el primer segundo [VEF1] 2.36 vs. 1.85 l; $p<0.05)$, mejor CVF (2.95 vs. 2.45 l; $p<0.05)$ y mejor relación VEF1/CVF (78 vs. 74; $p<0.05)$. Los sujetos

\author{
Correspondence: \\ *Saúl Huerta Ramírez \\ Plan de San Luis, s/n \\ Col. Ticomán, Del. Gustavo A. Madero \\ C.P. 07320 , Ciudad de México, México \\ E-mail: saul.huerta@hotmail.com
}

Date of reception: 08-12-2017

Date of acceptance: 11-04-2018

DOI: 10.24875/CIRUE.M18000025
Cir Cir. 2018;86:156-162

Contents available at PubMed www.cirugiaycirujanos.com 
hipertensos presentaron menores volúmenes en VEF1 (1.91 vs. 2.38; $p<0.05)$ y CVF (2.49 vs. 2.99; $p<0.05)$ Conclusión: No existe diferencia en los volúmenes espirométricos de pacientes con síndrome metabólico al compararlos con sujetos metabólicamente sanos. Solo la obesidad central y la hipertensión arterial se asocian con disminución del VEF1 y la CVF. Un hallazgo inesperado es la correlación negativa entre los valores de colesterol HDL y la función pulmonar.

PALABRAS CLAVE: Espirometría. Síndrome metabólico. Pulmón. Colesterol HDL.

\section{Background}

Metabolic syndrome (MetS) is defined as a group of clinical features that include abdominal obesity, hyperglycemia, elevated triglycerides, high blood pressure and high-density lipoprotein (HDL) cholesterol low values'. This syndrome is highly frequent in the world population, and its prevalence using the NCEP-ATPIII diagnostic criteria has been reported in up to $22 \%$ of the population in developed countries and $26 \%$ in the Mexican population ${ }^{2,3}$.

MetS constitutes an important risk factor for cardiovascular disease (myocardial infarction, stroke, arterial insufficiency), as well as for the development of type 2 diabetes mellitus. Recent reports indicate that MetS can influence on the development of non-alcoholic fatty liver disease and even on various types of cancer ${ }^{4}$. Currently, evidence is being gathered on the impact MetS could have on different aspects of lung function ${ }^{5}$.

There are some studies in Asian and North American populations indicating that MetS has certain association with a restrictive pulmonary pattern; however, controversy remains on the relative contribution of each individual component of the syndrome to pulmonary pathology ${ }^{6}$. It has been suggested that each component of the metabolic syndrome may have different influence on respiratory pathophysiology according to ethnic group and gender ${ }^{7}$.

Given that the relationship between MetS and the pulmonary function has been little studied in Latin American population, and knowing that this possible association may have important implications in the management of these patients, ${ }^{8}$ the purpose of this study is to analyze the effect MetS and each one of its components have on pulmonary volumes as measured by spirometry in Mexico City inhabitants.

\section{Method}

A convenience-sampling, analytical, cross-sectional study with was carried out, with eligible subjects who were treated at different outpatient services of the
Ticomán General Hospital in Mexico City during the first semester of 2017 being invited to participate. Individuals from 18 to 75 years of age without known lung disease or risk exposure for pulmonary pathology, who agreed to answer a questionnaire and give a blood sample, and who were able to perform the maneuvers required by the spirometry study were included.

Subjects who agreed to participate were asked to complete a questionnaire in order to record demographic variables such as gender, age, known pathologies and exposure to pulmonary risk factors. Anthropometric measurements were carried out (weight, height, body mass index and waist circumference) and blood pressure was recorded, following the guidelines established by the World Health Organization. Fasting blood samples were taken for the determination of glucose, triglycerides and HDL-cholesterol. Glucose was measured using the glucose oxidase method with a Beckman Coulder DxC600 equipment; triglycerides and HDL-cholesterol were measured with the DxC600 automated analyzer.

Based on the questionnaire results, anthropometric measurements and laboratory tests, the subjects were diagnosed with or without MetS. In accordance with the harmonized criteria published in 2009 by the Joint Scientific Statement, ${ }^{9}$ MetS was diagnosed when the subject met at least three of the following: glucose > $100 \mathrm{mg} / \mathrm{dL}$ or being on treatment for type 2 diabetes; waist circumference $>90 \mathrm{~cm}$ in men and $>80 \mathrm{~cm}$ in women; triglycerides $>150 \mathrm{mg} / \mathrm{dL}$ or on treatment to decrease them; HDL-cholesterol $<40 \mathrm{mg} / \mathrm{dL}$ in men and $<50 \mathrm{mg} / \mathrm{dL}$ in women and blood pressure $>140 / 90 \mathrm{~mm} / \mathrm{Hg}$ or being on antihypertensive treatment.

Finally, the patients underwent a simple spirometry study with the Medizintechnik TrueFlow Easy on PC spirometer. Subjects with chest pain, recent eye, abdominal or orthopedic surgery, using supplemental oxygen or unable to make maximal inspiratory or expiratory effort were excluded from spirometry. The study was carried out by trained medical personnel. Three acceptable efforts were required and only A, B and $C$ quality results were included according to the American Thoracic Society guidelines and the 
interpretation was with adherence to the values predicted by NAHNES III.

Data statistical analysis was performed using the STATA 11.0 program. Descriptive statistics were reported using frequencies and percentages for nominal variables, as well as means or medians (as appropriate) for quantitative variables. For inferential statistics, the means of lung parameters of interest were compared between the groups of subjects according to their metabolic characteristics. Simple correlations were established between some metabolic and spirometry variables.

\section{Results}

One-hundred and ten individuals were included in the study, out of whom 90 were women $(82 \%)$ and 20 men (18\%). Of the total sample, 71 subjects $(65 \%)$ met the criteria for MetS: 61 (55\%) had the hyperglycemia factor, 91 (83\%) had increased waist circumference, 67 (62\%) had elevated triglycerides, 74 (67\%) had low HDL-cholesterol and 44 (40\%) had high blood pressure (Table 1).

When the spirometric volumes of individuals with and without SMet were compared, we found no statistically significant difference (Table 2).

Regarding the analysis of each MetS factor and its impact on pulmonary volumes, subjects with increased waist circumference were found to have lower forced vital capacity (FVC) (2.72 vs. $3.11 \mathrm{~L} ; \mathrm{p}=0.04$ ) than subjects with normal waist circumference. Individuals with high blood pressure had lower forced expiratory volume in 1 second (FEV1) (1.91 vs. $2.38 \mathrm{~L}$; $p=0.01)$ and lower FVC (2.49 vs. $2.99 ; p=0.01)$ than non-hypertensive subjects. The hypertriglyceridemia and hyperglycemia factors were not associated with spirometry alterations. Individuals with normal or increased HDL-cholesterol had lower FEV1 volumes (2.36 vs. $1.85 \mathrm{~L}: \mathrm{p}=0.01)$, FVC (2.95 vs. $2.45 ; p=0.01$ ) and FEV1/FVC ratio (0.78 vs. $0.74 ; p=0.01)$ than subjects with low HDL-C (Table 3 ).

To establish the degree of association HDL-cholesterol has with the decrease in lung volumes, a simple linear regression was performed, where a significant inverse correlation was observed between $\mathrm{HDL}$-cholesterol and all three pulmonary parameters (Table 4 and Figs. 1 - 3).

\section{Discussion}

Our results indicate that, in a sample of the Mexican population, there is no difference between the lung
Table 1. Clinical characteristics of the sample

\begin{tabular}{|c|c|c|}
\hline Characteristic (N = 110) & Frequency & $(\%)$ \\
\hline \multicolumn{3}{|l|}{ Gender } \\
\hline Males & 20 & (18) \\
\hline Females & 90 & (82) \\
\hline \multicolumn{3}{|l|}{ Metabolic syndrome } \\
\hline With & 71 & (65) \\
\hline Without & 39 & (35) \\
\hline \multicolumn{3}{|l|}{ Hyperglycemia } \\
\hline With & 61 & (55) \\
\hline Without & 49 & (55) \\
\hline \multicolumn{3}{|l|}{ Waist circumference } \\
\hline Normal & 19 & (17) \\
\hline Increased & 91 & (83) \\
\hline \multicolumn{3}{|l|}{ Triglycerides } \\
\hline Normal & 41 & (38) \\
\hline$>150 \mathrm{mg}$ & 67 & (62) \\
\hline \multicolumn{3}{|l|}{ HDL-cholesterol } \\
\hline Normal & 36 & (33) \\
\hline Low & 74 & (67) \\
\hline \multicolumn{3}{|l|}{ High blood pressure } \\
\hline Without & 66 & (60) \\
\hline With & 44 & (40) \\
\hline \multicolumn{3}{|l|}{ Quantitative (N = 110) } \\
\hline & Median & p25-75 \\
\hline Age (years)* & 54 & \pm 13 \\
\hline BMI & 27.5 & 25.3-31.4 \\
\hline WC $(\mathrm{cm})$ & 95 & $88-100$ \\
\hline Glucose (mg/dL) & 98.5 & $91-111$ \\
\hline Triglycerides (mg/dL) & 173 & $129-238$ \\
\hline HDL-cholesterol (mg/dL) & 43 & $35-51$ \\
\hline
\end{tabular}

*Variable with parametric distribution, mean and standard deviation are reported. All variables followed a non-parametric distribution, and median and 25-75 percentiles are therefore reported.

HDL: high-density lipoprotein; BMI: body mass index; WC: waist circumference.

volumes of patients who met MetS criteria (according to the 2009 harmonized criteria) and those of patients without the syndrome. However, when the impact on lung function of each component of the syndrome was separately analyzed, we observed that subjects with the increased waist circumference factor (central obesity) have lower FVC than those without this type of obesity, and that subjects with the high blood pressure factor have lower FEV1 and FVC than non-hypertensive individuals. Conversely, subjects with the low HDL-cholesterol component had higher spirometry volumes than subjects with normal or high HDL-cholesterol.

Previous studies with case-control design ${ }^{10}$ initially identified patients with pulmonary obstructive and 
Table 2. Spirometric volumes in patients with and without metabolic syndrome

\begin{tabular}{lccr}
\hline Pulmonary function by spirometry & Without metabolic syndrome $(\mathbf{n = 3 9 )}$ & With metabolic syndrome $(\mathbf{n = 7 1 )}$ & $\mathbf{p}$ \\
\hline FEV1 (L) & 2.16 & 2.21 & 0.71 \\
FEV1\% & 88.3 & 87.9 & 0.90 \\
FVC (L) & 2.79 & 2.79 & 0.9 \\
FVC\% & 89.6 & 87.6 & 0.47 \\
FEV1/FVC & 75 & 78 & 0.10 \\
\hline
\end{tabular}

FVC: forced vital capacity; FEV1: forced expiratory volume in 1 second.

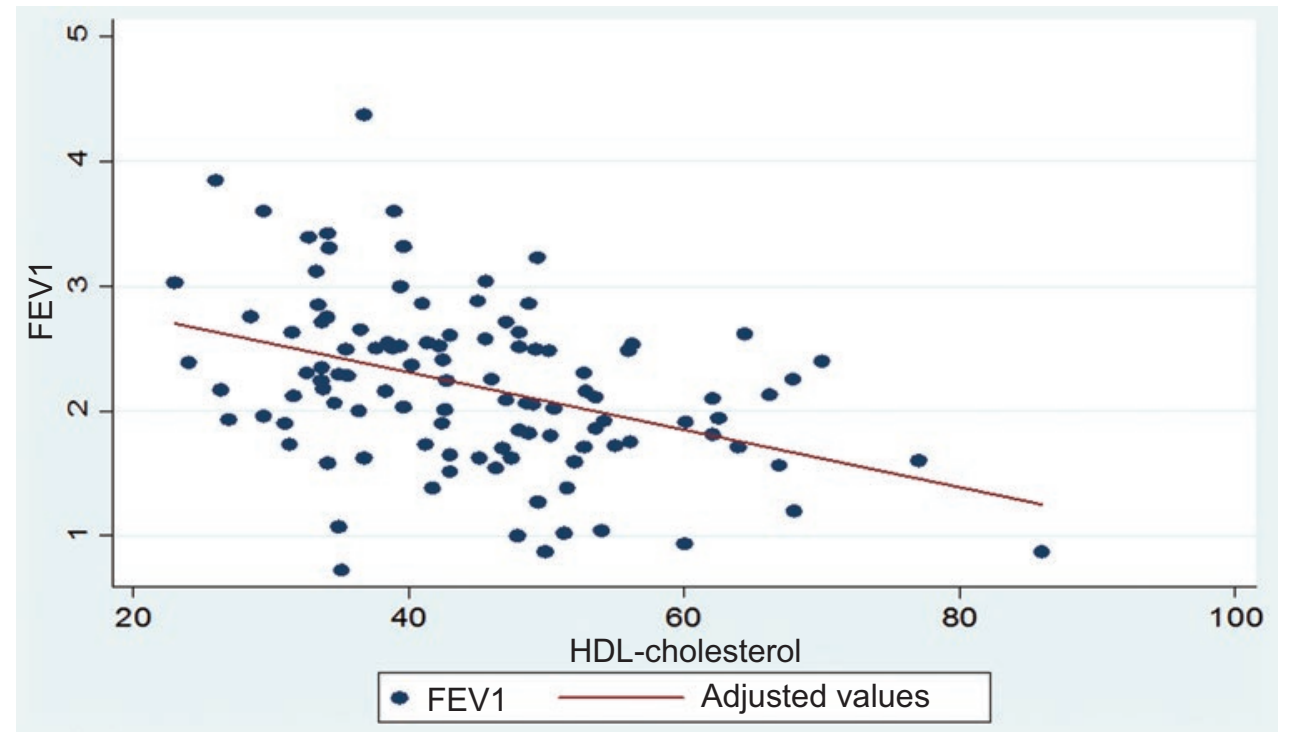

Figure 1. Simple linear regression between FEV1 (L) and HDL-cholesterol (mg/dL).

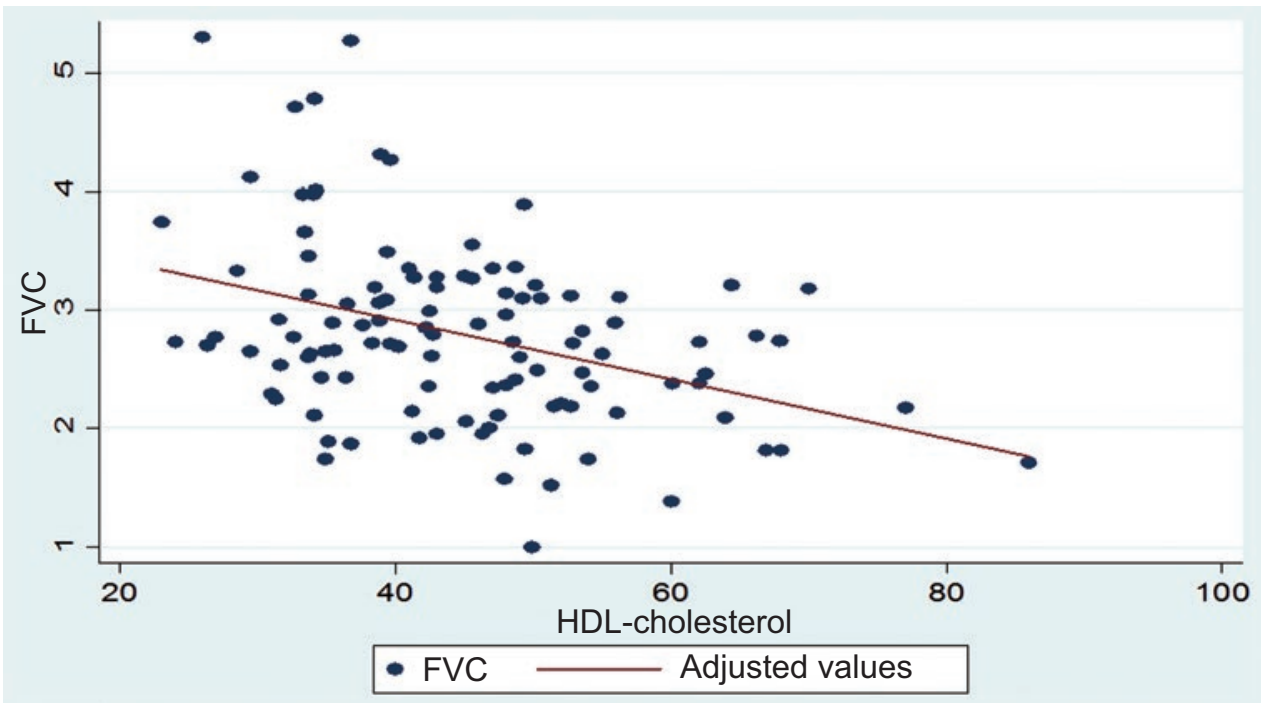

Figure 2. Simple linear regression between FVC $(L)$ and HDL-cholesterol (mg/dL).

restrictive patterns in order to analyze the prevalence of MetS among them, and noted that both patterns were associated with higher presence of MetS. Marquis et al. ${ }^{11}$ reported, in 38 patients with COPD and 34 controls, a prevalence of MetS of 47 and $21 \%$, respectively, while a study in Taiwan ${ }^{12}$ that analyzed more than 40,000 subjects showed that the restrictive, but not the obstructive pulmonary pattern, was 


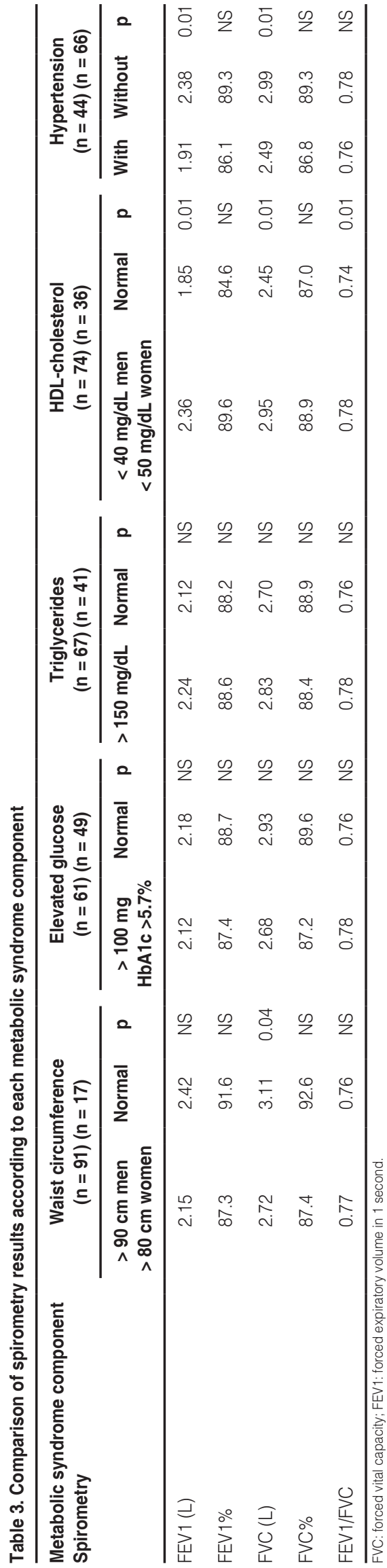

Table 4. Correlation (by simple linear regression) between pulmonary function and HDL-cholesterol

\begin{tabular}{llccc}
\hline HDL-cholesterol & Spirometry & $\boldsymbol{\beta}$ & $\mathbf{R}$ & $\mathbf{p}$ \\
\hline & FEV1 & -0.02 & -0.04 & 0.001 \\
& FVC & -0.02 & -0.38 & 0.001 \\
& FEV1/FVC & -0.001 & -0.22 & 0.01 \\
\hline
\end{tabular}

$\beta$ : correlation coefficient beta; FVC: forced vital capacity; R: correlation; FEV1: forced expiratory volume in 1 second.

associated with the presence of MetS (odds ratio: 1.22). The design of these approaches differs from ours, since they started from the diagnosis of pulmonary restrictive or obstructive functional alteration to observe the prevalence of MetS, while we first identified the presence MetS to then look for the spirometric volumes behavior between subjects with and without the syndrome.

We found a similar approach to ours, reporting lung parameters according to the presence of MetS and each of its components, in three reports. The first one ${ }^{13}$, with data from the Strong Heart Study that explores Native American populations, found that FEV1, FEV1\%, FVC and FVC\% mean values were lower in subjects with MetS. This study also analyzed two MetS components and their effect on pulmonary function separately, and found that both diabetes mellitus and central obesity were associated with a decrease in pulmonary parameters. An analysis in the North American population derived from the NANHES ${ }^{8}$ cohort reported that a pulmonary function restrictive pattern is slightly more prevalent in subjects with MetS, and that each one of the five components is associated with a mild pulmonary restriction as well. A research carried out in $\mathrm{Korea}^{14}$ suggested a possible influence of gender on the effect MetS has on the lung. They studied 1370 subjects with MetS and observed that only men presented a slight decrease in FEV1 and FVC. This study also found that not all MetS factors have a negative impact on spirometry; in fact, HDL-cholesterol and waist circumference are associated with better pulmonary volumes. The latter finding is consistent with our results.

As can it be observed, in these reports there are certain concordances, but also discrepancies a regards the effect that different MetS components have on pulmonary function. This situation might be explained not only by the different methodology employed and the type of subjects included in each investigation, but also by genetic and ethnic differences that 


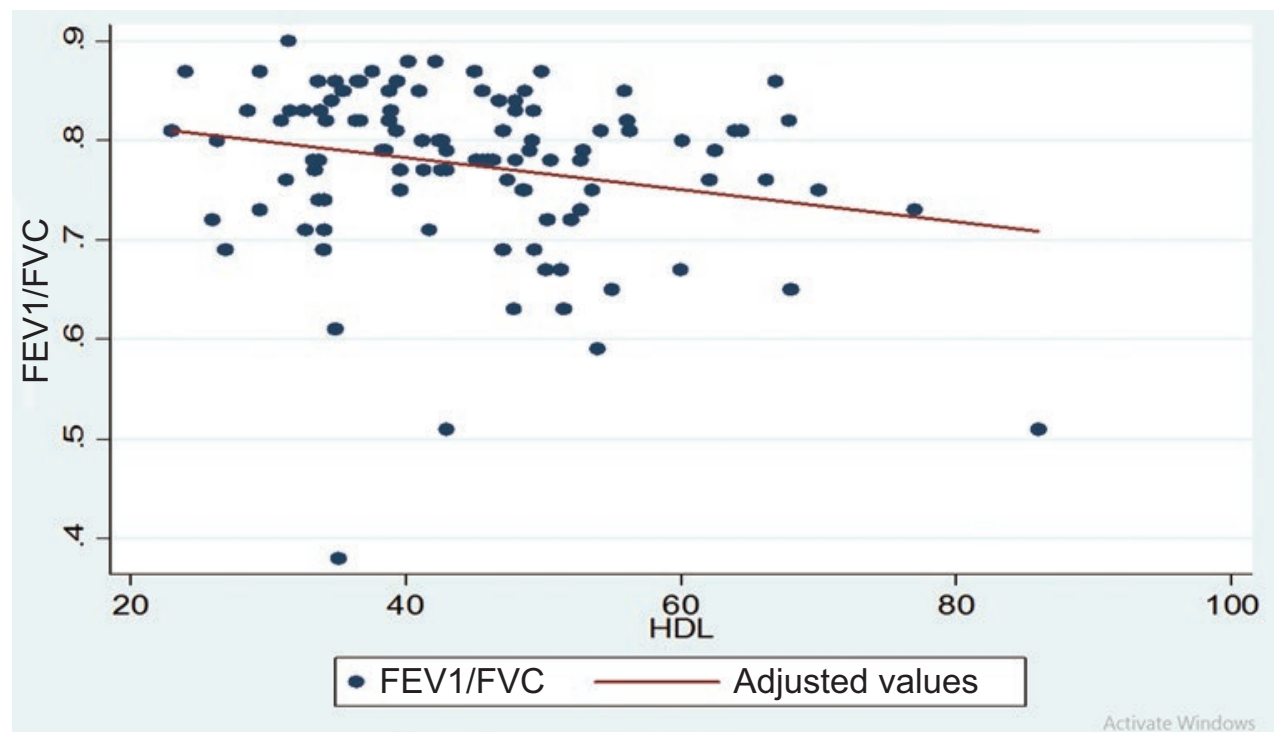

Figure 3. Simple linear regression between the FEV1/FVC index (\%) and HDL-cholesterol ( $\mathrm{mg} / \mathrm{dL})$.

determine MetS components different behaviors, especially in the case of lipoproteins ${ }^{15}$.

In our study, we observed that subjects with normal or high HDL-cholesterol values have lower pulmonary volumes than subjects with low HDL. This is a finding we considered to be "unexpected" since, given the anti-atherogenic, anti-inflammatory, antioxidant and even antiapoptotic functions attributed to this lipoprotein, it would be speculated that elevated values thereof would constitute a beneficial factor for pulmonary function ${ }^{16-18}$. Although it is true that HDL-cholesterol has been attributed the aforementioned functions, recently, the HDL-cholesterol paradigm as a protector for atherogenesis has been changing, and an example of this is the demonstration that the cholesterol efflux function, which was initially attributed to this lipoprotein, is independent of it. In fact, its anti-inflammatory and cholesterol-mobilizing capacity has been found to be seriously affected by HDL-associated protein oxidation, and that this dysfunctional HDL can even be pro-inflammatory ${ }^{19}$. This new approach to HDL-cholesterol physiological aspects might partly explain our finding that subjects with elevated values have lower pulmonary volumes.

In line with us, a genetic and molecular study, conducted in two ethnical groups (African-Americans and European-Americans), has reported two polymorphis$\mathrm{ms}$ in genes associated with apolipoprotein M (APOM) that are related to a pulmonary function decrease. APOM is a lipoprotein that accompanies HDL-cholesterol, and a change in its gene expression alters $\mathrm{HDL}$-cholesterol quality and function. In fact, this same study has found that high HDL-cholesterol values are associated with a decreased FEV1/FVC ratio ${ }^{15}$.

The present study has several limitations. Being a cross-sectional study, no causal relationship can be established between metabolic factors and pulmonary alterations. The population it was carried out with might not be representative of the Mexican general population, since it was conducted in subjects who were a captive population of a hospital. The sample size is limited and the conclusions should not be generalized. More studies are required, and in different populations, exploring the effect MetS factors have on the pulmonary function, given that there are some clues that this association is variable in each ethnic group.

\section{Conclusions}

In the Mexican population, subjects with MetS show a similar pulmonary function to that in subjects without MetS. However, each one of the MetS components plays a different role in pulmonary function, since subjects with increased waist circumference, high blood pressure and normal or high HDL-cholesterol have lower volumes by spirometry than subjects without these factors.

\section{References}

1. Eckel RH, Grundy SM, Zimmet PZ. The metabolic syndrome. Lancet. 2005;365:1415-28.

2. Beltrán $\mathrm{H}$, Harhay $\mathrm{MO}$, Harhay $\mathrm{MM}$, McElligott $\mathrm{S}$. Prevalence and trends of metabolic syndrome in the adult U.S. population, 1999-2010. J Am Coll Cardiol. 2013;62:697-703.

3. Wacher NH. Epidemiología del síndrome metabólico. Gac Med Mex. 2009;145:384-91.

4. Brede S, Serfling G, Klement J, Schmid SM, Lehnert H. Clinical scenario of the metabolic syndrome. Visc Med. 2016;32:336-41. 
5. Leone N, Courbon D, Thomas F, Bean K, Jégo B, Leynaert B, et al. Lung function impairment and metabolic syndrome: the critical role of abdominal obesity. Am J Respir Crit Care Med. 2009;179:509-16.

6. Baffi CW, Wood L, Winnica D, Strollo PJ, Gladwin MT, Que LG, et al. Metabolic syndrome and the lung. Chest. 2016;149:1525-34.

7. Chen WL, Wang CC, Wu LW, Kao TW, Chan JY, Chen YJ, et al. Relationship between lung function and metabolic syndrome. PLoS One. 2014;9:e108989.

8. Ford ES, Cunningham TJ, Mercado $\mathrm{Cl}$. Lung function and metabolic syndrome: findings of National Health and Nutrition Examination Survey 2007-2010. J Diabetes. 2014;6:603-13.

9. Alberti KG, Eckel RH, Grundy SM, Zimmet PZ, Cleeman JI, Donato KA, et al. Harmonizing the metabolic syndrome: a joint interim statement of the International Diabetes Federation Task Force on Epidemiology and Prevention; National Heart, Lung, and Blood Institute; American Heart Association; World Heart Federation; International Atherosclerosis Society; and International Association for the Study of Obesity. Circulation. 2009;120:1640-5

10. Reed RM, Iacono A, DeFilippis A, Eberlein M, Girgis RE, Jones S. Advanced chronic obstructive pulmonary disease is associated with high levels of high-density lipoprotein cholesterol. J Heart Lung Transplant. 2011;30:674-8.

11. Marquis K, Maltais F, Duguay V, Bezeau AM, LeBlanc $P$, Jobin J, et al. The metabolic syndrome in patients with chronic obstructive pulmonary disease. J Cardiopulm Rehabil. 2005;25:226-32.
12. Lin WY, Yao CA, Wang HC, Huang KC. Impaired lung function is associated with obesity and metabolic syndrome in adults. Obesity (Silver Spring). 2006;14:1654-61.

13. Yeh F, Dixon AE, Marion S, Shaefer C, Zhang Y, Best LG, et al. Obesity in adults is associated with reduced lung function in metabolic syndrome and diabetes: the Strong Heart Study. Diabetes Care. 2011;34:2306-13.

14. Bae MS, Han JH, Kim JH, Kim YJ, Lee KJ, Kwon KY. The relationship between metabolic syndrome and pulmonary function. Korean $\mathrm{J}$ Fam Med. 2012;33:70-8.

15. Burkart KM, Manichaikul A, Wilk JB, Ahmed FS, Burke GL, Enright P, et al. APOM and high-density lipoprotein cholesterol are associated with lung function and per cent emphysema. Eur Respir J. 2014; 43:1003-17.

16. Gordon S, Durairaj A, Lu JL, Davidson WS. High-density lipoprotein proteomics: identifying new drug targets and biomarkers by understanding functionality. Curr Cardiovasc Risk Rep. 2010;4:1-8.

17. Pian MS, Dobbs LG. Lipoprotein-stimulated surfactant secretion in alveolar type II cells: mediation by heterotrimeric G proteins. Am J Physiol. 1997;273:634-9.

18. Kolleck I, Schlame M, Fechner H, Looman AC, Wissel H, Rüstow B. HDL is the major source of vitamin $\mathrm{E}$ for type II pneumocytes. Free Radic Biol Med. 1999;27:882-90.

19. Khera AV, Cuchel M, de la Llera-Moya M, Rodrigues A, Burke MF, Jafri K, et al. Cholesterol efflux capacity, high-density lipoprotein function, and atherosclerosis. N Engl J Med. 2011;364:127-35. 